\title{
Stress as a factor contributing to obesity in patients qualified for bariatric surgery - studies in a selected group of patients (a pilot study)
}

\author{
Iwona Boniecka ${ }^{1}$, Helena Wileńska ${ }^{2}$, Anna Jeznach-Steinhagen ${ }^{1}$, Aneta Czerwonogrodzka-Senczyna ${ }^{1}$, \\ Marzena Sekuła ${ }^{3}$, Krzysztof Paśnik ${ }^{4}$ \\ ${ }^{1}$ Department of Human Nutrition, Medical University of Warsaw, Warsaw, Poland \\ ${ }^{2}$ Faculty of Health Sciences, Medical University of Warsaw, Warsaw, Poland \\ ${ }^{3}$ Interdisciplinary Doctoral Studies, SWPS (Szkoła Wyższa Psychologii Społecznej) Unviersity of Social Sciences and Humanities, Warsaw, \\ Poland \\ ${ }^{4}$ Department of General, Oncologic, Metabolic and Thoracic Surgery, Military Institute of Medicine, Warsaw, Poland
}

Videosurgery Miniinv 2017; 12 (1): 60-67 DOI: https://doi.org/10.5114/wiitm.2016.65078

\begin{abstract}
Introduction: Recently, the incidence of obesity, especially extreme obesity, has significantly increased. It is connected with inappropriate lifestyle, including a high calorie diet, psychological and genetic factors, some medications, diseases or infectious factors. Nowadays, the consumption of food is not only to satisfy a physiological need, but also fulfils psychological needs. The most effective method of morbid obesity treatment is metabolic surgery. Moreover, food is considered to be a reward and method of coping with stress. In order to improve the efficiency of the surgical treatment, it seems significant to assess the effects of psychological factors on eating behaviours.

Aim: To evaluate the effects of stress on eating habits that increase the risk of extreme obesity.

Material and methods: The study included 50 subjects qualified for bariatric surgery. The authors' own questionnaire and standardised PSS-10 questionnaire by Cohen, Kamarcki and Mermelstein adapted by Juczyński and Ogińska-Bulik were used.

Results: These questionnaires indicated that patients felt a moderate levels of stress but with a tendency for high levels. The majority of respondents declared an increased appetite due to stress-causing factors. Reasons for snacking most frequently included negative emotions and feeling like eating something. Consumption of additional snacks was a way of coping with stress. Most frequently the subjects ate sweets and salty snacks, but also sandwiches, nuts, fruit and alcohol beverages.

Conclusions: Psychological support may help morbidly obese people both to change nutritional habits and to cope with stress.
\end{abstract}

Key words: extreme obesity, stress, eating habits.

\section{Introduction}

Recently, the incidence of obesity, especially extreme obesity, has significantly increased [1]. Between 1980 and 2013 the number of people who were overweight or obese increased 2.5 times: from
857 million to 2.1 billion [1]. An inappropriate lifestyle, including a poorly balanced diet, can cause a sudden increase in body weight. Other factors, such as genetic factors, some medications, diseases or infectious factors also play a significant role [1, 2].

\section{Address for correspondence}

Iwona Boniecka, Department of Human Nutrition, Medical University of Warsaw, 27 E. Ciołka St, 01-445 Warsaw, Poland,

phone: +48 609408 944, e-mail: iboniecka@gmail.com 
Psychosocial factors are especially important. Difficulties in regulating emotions and chronic stress not only favour increased body weight but also make it difficult to reduce the body weight [2-4]. Nowadays, the consumption of food is not only for fulfilment of a physiological need (to satisfy hunger) but also performs psychological functions (e.g. eating gives us pleasure) [5]. In such cases control over the amount of consumed food and its nutritional and energetic value is lost. Moreover, food is often considered to be a reward, a method to cope with problems; therefore in stressful situations people reach for products that are easily available - of low nutritional quality, highly processed, rich in saturated fatty acids, such as trans fatty acids, as well as simple carbohydrates, and low in fibre [2-5]. Such a diet not only favours obesity but also its complications such as diet-associated diseases including type 2 diabetes, dyslipidaemia, and circulatory diseases $[2,4,6]$. Studies indicate that obese people more often suffer from depression than slim individuals [2-10]. It may be observed in even $50 \%$ of patients qualified for bariatric surgery [7]. Bariatric procedures are the most effective treatment of morbid obesity, and their number is steadily increasing [5, 11-13]. In Poland in 2014, 499 bariatric procedures were performed, with $96.4 \%$ done laparoscopically [11]. Therefore in order to prevent and treat extreme obesity, as well as to improve the efficiency of the surgical treatment, it seems important to assess the effects of psychological factors on chosen nutritional habits.

\section{Aim}

The aim of the study was to evaluate the effects of stress on nutritional habits that increase the risk of obesity, especially extreme obesity.

\section{Material and methods}

The study was conducted at the Department of General, Oncological and Metabolic Surgery and Thoracic Surgery, Military Institute of Medicine in Warsaw between October 2015 and March 2016. The study group included 50 people, including 31 women and 19 men. The sample selection was targeted. The inclusion criterion was qualification for bariatric surgery (age 18-60 years, BMI $\geq 40 \mathrm{~kg} / \mathrm{m}^{2}$ or $\mathrm{BMI} \geq 35 \mathrm{~kg} / \mathrm{m}^{2}$ with coexisting complications of obesity such as metabolic syndrome, cardiovascular diseases, joint degeneration, psychological prob- lems, failure of previous conservative treatment, further body weight gain after a body weight loss as a result of conservative treatment) $[12,13]$. A proprietary questionnaire including 10 closed questions and personal information was used. The survey questions regarded current nutritional behaviour of patients including the following elements: number of meals, snacking between meals (grazing), effects of stress on the appetite and consumption of some products. Personal information included sociodemographic questions regarding sex, age, body weight and height (in order to calculate BMI) as well as education and work position. In the case of some questions the response rates did not sum up to 100 as it was possible to indicate more than one answer.

The Perceived Stress Scale (PSS-10) by Cohen, Kamarcki and Mermelstein adapted by Juczyński and Ogińska-Bulik was also used [14]. It includes 10 questions regarding various subjective feelings associated with personal problems and incidents, and methods how to behave and cope with them. It allows one to determine the levels of stress associated with one's own personal situation in the last month. Respondents answered questions based on the Likert scale including the range of $0-4$ (where $0=$ never, 1 = almost never, 2 = sometimes, 3 = fairly often, $4=$ very often). The overall rate of perceived stress is calculated as the sum of all the answers. The higher the score, the higher the intensity of perceived stress. The questionnaire is normalized to sten results. The sten score of 1 to 4 is considered to be low stress, 5-6 indicates moderate stress, whereas 7-10 indicates high levels of stress.

\section{Statistical analysis}

Results were analysed with Microsoft Excel and SPSS for Windows 21.0. The $\chi^{2}$ test and Student's $t$-test at the significance level of $p<0.05$ were applied.

\section{Results}

Almost $90 \%$ of patients consumed at least 3 meals a day, whereas $58 \%$ consumed 4 or more, and $28 \%$ of them consumed 3 meals. The majority of patients $(86 \%)$ snacked between meals. The most common reasons included feeling like eating something (52\%) and anxiety (50\%). Twenty-six percent of respondents indicated the need to see food and hunger, about one in five (22\%) indicated the need to chew, followed by the smell of food (18\%) and social group 
(18\%). For the majority of respondents (60\%) eating additional snacks helped to reduce stress. Others did not observe such relationships. Eighty percent of respondents reported experiencing increased appetite when a stress factor was present. Despite the fact that a statistical analysis did not show any significant correlations between the sex of respondents and increased appetite under stress conditions, slightly more women compared to men experienced increased appetite ( $83 \%$ vs. $73 \%)$. A great majority of respondents (88\%) did not experience waking up at night due to hunger after a stressful day at work. With regard to the question whether they controlled the amount of consumed food during social events, $64 \%$ of responders said yes. Increased appetite was reported by $14 \%$ of respondents in such situations, and $12 \%$ of them reached for food without thinking. A small group of respondents answered "I don't want hosts to feel hurt" and "In such situations I eat because the meals are more tasty for me" $(6 \%$ and $4 \%$, respectively). When a stress factor was present, the following products were consumed especially more frequently (response 2 and 3): sweets (52\%), sandwiches (44\%), cold cuts (40\%), nuts and fruit (34\%), alcohol and salty snacks (30\%), and significantly more (response 3): sweets (36\%) (Table I).

The analysis of individual responses from the PSS-10 questionnaire indicated at the turn of the last 4 weeks that within the last month $64 \%$ of patients were nervous and stressed fairly or very often, and half of them were stressed due to events that happened unexpectedly (Table II). More than $72 \%$ of patients felt anger because things were outside of their control, and $66 \%$ felt they were not able to control the important things in their lives; and responses of fairly often and very often were indicated by $36 \%$ and $34 \%$ of respondents, respectively. Almost $60 \%$ of patients could not cope with all the things they had to do, and the responses of fairly often and very often were selected by $26 \%$. At the same time, $70 \%$ of respondents were able to handle personal problems fairly often and very often, and $60 \%$ felt things were going their way. The great majority of respondents claimed they were able to control their irritation and felt they were on top of things ( $96 \%$ and $90 \%$, respectively), and responses of fairly often and very often accounted for $60 \%$.

In the study group the mean value of sten scores corresponding to a value of points scored in the PSS10 scale was 6.22 out of 10 . It is a value classified as a moderate level of stress, with a tendency for high levels of stress. Subjects who assessed their stress levels as low in the original questionnaire were exposed to moderate stress according to the results of the PSS-10 questionnaire. The value of sten scores of 5-6 was predominant in this group. Among subjects

Table I. Effects of stress factors on the consumption of some food products in a selected group of patients (\% of responses)

\begin{tabular}{|llccc|}
\hline Food products & \multicolumn{3}{c|}{ Dietary changes under stressors (\%) } \\
\cline { 2 - 5 } & No changes & $\begin{array}{c}\text { Hardly any } \\
\text { changes }\end{array}$ & I eat a bit more & $\begin{array}{c}\text { I eat significantly } \\
\text { more }\end{array}$ \\
\hline Ice cream & 58 & 20 & 10 & 12 \\
\hline Dried fruits & 66 & 14 & 14 & 6 \\
\hline Cold cuts, sausages & 42 & 18 & 32 & 18 \\
\hline Sandwiches & 40 & 16 & 26 & 8 \\
\hline Vegetables & 52 & 22 & 18 & 18 \\
\hline Fruits & 40 & 26 & 10 & 36 \\
\hline Yeast-based dough, sweet buns & 60 & 24 & 16 & 18 \\
\hline Sweets such as chocolate, chocolates, bars & 26 & 22 & 12 & 20 \\
\hline Crisps, salty sticks, crackers & 62 & 8 & 14 & 18 \\
\hline Nuts & 40 & 26 & 12 & 36 \\
\hline Alcoholic beverages, beer, wine & 60 & 10 & 16 & 8 \\
\hline
\end{tabular}


Table II. Results of responses to individual questions of the PSS-10 questionnaire (\% of responses)

\begin{tabular}{|c|c|c|c|c|c|}
\hline Responses/score & 0 & 1 & 2 & 3 & 4 \\
\hline $\begin{array}{l}\text { In the last month, how often have you been upset because of something that } \\
\text { happened unexpectedly? }\end{array}$ & 2 & 12 & 32 & 34 & 20 \\
\hline $\begin{array}{l}\text { In the last month, how often have you felt that you were unable to control the } \\
\text { important things in your life? }\end{array}$ & 12 & 22 & 32 & 20 & 14 \\
\hline In the last month, how often have you felt nervous and stressed? & 0 & 8 & 28 & 26 & 38 \\
\hline $\begin{array}{l}\text { In the last month, how often have you felt confident about your ability to handle } \\
\text { your personal problems? }\end{array}$ & 6 & 8 & 16 & 38 & 32 \\
\hline In the last month, how often have you felt that things were going your way? & 2 & 4 & 34 & 40 & 20 \\
\hline $\begin{array}{l}\text { In the last month, how often have you found that you could not cope with all } \\
\text { the things that you had to do? }\end{array}$ & 14 & 28 & 32 & 12 & 14 \\
\hline $\begin{array}{l}\text { In the last month, how often have you been able to control irritations in your } \\
\text { life? }\end{array}$ & 0 & 4 & 38 & 38 & 20 \\
\hline In the last month, how often have you felt that you were on top of things? & 2 & 8 & 34 & 44 & 12 \\
\hline $\begin{array}{l}\text { In the last month, how often have you been angered because of things that } \\
\text { were outside of your control? }\end{array}$ & 10 & 16 & 38 & 20 & 16 \\
\hline $\begin{array}{l}\text { In the last month, how often have you felt difficulties were piling up so high } \\
\text { that you could not overcome them? }\end{array}$ & 14 & 22 & 38 & 10 & 16 \\
\hline
\end{tabular}

Where 1 means never, 4 means very often.

who declared their stress levels to be moderate, the sten score was mainly in the range $1-4$, indicating that their stress level was low. The results among respondents who assessed their stress levels to be high were similar to the PSS-10 score (sten score of 7-10).

With regard to the original survey questionnaire, almost half of respondents (48\%) stated that their work is associated with high levels of stress, and in $38 \%$ the stress levels were moderate. A statistical analysis showed a significant correlation between the position at work and the stress level of respondents (Table III). In a group of patients who were in a managerial post $75 \%$ of patients showed a high level of stress, whereas $47 \%$ of respondents who were not in a managerial post showed a moderate stress level.

\section{Discussion}

A growing impact of stress on lifestyle as well as on eating habits of societies in highly developed

Table III. Subjective stress levels and stress levels according to PSS-10 depending on patients' position (\% of responses)

\begin{tabular}{|c|c|c|c|c|}
\hline \multirow[t]{2}{*}{ Subjective } & \multicolumn{2}{|c|}{ Job position } & \multirow[t]{2}{*}{ Total } & \multirow[t]{2}{*}{$P$-value } \\
\hline & Managerial & Non-managerial & & \\
\hline Low & 0 & 23 & 14 & 0.04 \\
\hline Moderate & 25 & 47 & 38 & \\
\hline High & 75 & 30 & 48 & \\
\hline \multirow[t]{2}{*}{ According to PSS-10 } & \multicolumn{2}{|c|}{ Job position } & Total & $P$-value \\
\hline & Managerial & Non-managerial & & \\
\hline Low & 5 & 33 & 22 & 0.06 \\
\hline Moderate & 40 & 26 & 32 & \\
\hline High & 55 & 40 & 46 & \\
\hline
\end{tabular}


countries has been observed for many years [2-6] The results of our research showed that the vast majority of patients had at least three meals a day. The result, despite seeming surprisingly good, was confirmed in other studies $[15,16]$. In the study by Michell et al. [15] appraising eating habits of patients scheduled for bariatric surgery, $80 \%$ of the patients ate three meals daily or more, whereas $45 \%$ of them ate five or six times daily and therefore a bit less than in this study (58\%). Despite having frequent meals, a great many patients snacked between them, which could significantly have resulted in an increase of body weight. It happens because eating between meals causes hunger and satiety disorders as well as boosting excessive consumption of energy. It is believed to be one of the most important causes of weight gain following surgical treatment of obesity $[17,18]$. Our own research showed that most of the respondents snacked between the meals, which was confirmed in other studies [17, 18]. Colles et al. [18] examined 129 bariatric patients before and 1 year after surgery. Most pre-surgical grazers continued some type of snacking after surgery. Grazers lost less weight than non-grazers, reported less dietary restraint, greater hunger and disinhibition, more frequent daily eating episodes and showed a higher total energy intake. More symptoms of depression and poorer mental health were also observed. Similar results have been obtained by other authors [19, 20]. They showed that grazing patients had lower percentage excess weight loss (\%EWL), higher BMI values and higher levels of depressive symptoms and stress [19]. In a study on eating behaviour in adults before bariatric surgery, loss of eating control was reported by $43.4 \%$ of participants. About $16 \%$ satisfied criteria for binge eating disorder (BED). Factors that independently increased the odds of BED were e.g. eating more times per day, emotional problems, and having symptoms of alcohol use disorder, lower self-esteem and more depressive symptoms [20]. It is worth emphasizing that if patients were eating emotionally prior to surgery, these patterns can recur, although in a different form [17]. Very interesting findings were published by Zunker et al. Their post-bariatric surgery patients seemed to view grazing as a healthy eating behaviour characterized by mindful food choices that are consumed in small amounts frequently throughout the day. This may reflect physician and dietician recommendations regarding this style of eating after bariatric sur- gery [17]. At the same time, these authors claimed that grazing should have also been perceived as unhealthy especially if unplanned, and mindless. Based on this findings, they proposed the concept of grazing: frequently eating small amounts of food that post-bariatric patient may or may not perceive as mindful behaviour [17]. In the context of the results quoted it is worth highlighting that after bariatric surgery the depressive and stress symptoms, quality of life and binge eating symptoms improved $[18,19,21]$.

In our research stress was found to be one of the most frequent causes of eating between meals and moreover a large part of the patients reported an increase in appetite due to stressful situations. The connection between stress and snacking was also found in other studies [16-23]. The observations of Zellner et al. [23] showed that $73 \%$ of female respondents and $71 \%$ of men overate due to stress. These findings are practically identical to those of our study. The research by Boniecka et al. [22] revealed that nine out of ten subjects ate between meals due to stress. Also, the observations by Cymerys and Olek [24] revealed that the mental condition has an influence on eating habits of obese people. In their test group $35.2 \%$ of the respondents admitted that they had fits of overeating when experiencing anxiety.

Other important reason for grazing was feeling like eating something. Boniecka et al. [22] demonstrated that the second important cause of snacking (after anxiety) was feeling hunger. In our research $26 \%$ of participants confirmed the same reason for overeating. In the study by Ostrowska et al. [16] the respondents declared an increase in appetite at night. Mitchell et al. [20] showed that before bariatric surgery about $18 \%$ of patients fulfilled the criteria of night eating syndrome. However, our own research showed that the majority of the test-group subjects did not wake up hungry at night.

It was found that in stressful situations obese individuals eat emotionally and lose control over the amount and quality of consumed food [2-4, 17-26]. Our patients mainly craved products rich in calories such as sweets, nuts and sandwiches. Sandwiches as such should, however, be treated as a meal and not as a snack. Also, other authors [23] demonstrated that stress boosted consumption of sweet snacks. Furthermore, the respondents quit fruit only to replace it with candy. Whereas in the group exposed to a low stress factor the respondents more often went for 
fruit with a low sugar content. Lewandowska-Skop et al. [26] also found a tendency for increased consumption of simple sugars due to stress. The diet of the obese women tested by them was characterized by a high content of refined carbohydrates the consumption of which rose in company with an increase of the BMI index. On the other hand, the study by Barrington et al. [27] revealed that participants influenced by negative emotions consumed more not only sweet but also fatty products. The study by Born et al. [28] showed that people suffering from stress more frequently went for crispy products. In our study $22 \%$ of the respondents justified their snacking with a strong need to munch or bite something. It is also worth mentioning that under the influence of negative thoughts our participants reached for alcohol. This is a particularly hazardous phenomenon since it can cause not only weight gain but also hypertriglyceridemia and it can also lead to addiction. It is well known that stress is an important factor in the development of addiction [4, 20]. One should also emphasize that addiction to alcohol is a contraindication for bariatric surgery [29].

As claimed by Yau and Potenza [4], uncontrollable stress changed eating patterns and increased the consumption of hyperpalatable, high-caloric foods; over time, this could lead to changes in allostatic load and trigger neurobiological adaptations that promote increasingly compulsive behaviour. This association may be mediated by alterations in the hypothalamic-pituitary-adrenal (HPA) axis, glucose metabolism, insulin sensitivity, and other appetite-related hormones and hypothalamic neuropeptides. At the neurocircuitry level, chronic stress may affect the mesolimbic dopaminergic system and other brain regions involved in stress. Together, these may synergistically potentiate reward sensitivity, food preference, and the wanting and seeking of hyperpalatable foods, as well as inducing metabolic changes that promote weight and body fat mass. What is more, understanding the associations and interactions between stress, neurobiological adaptations, and obesity is important in the development of effective prevention and treatment strategies for obesity and related metabolic diseases [4]. Richardson et al. [30] found that perceived stress was directly and positively associated with severe obesity, independent of eating behaviours and diet quality.

The findings from the study by Barrington et al. [27] where the scale PSS-10 was also used for the assessment of stress level showed that the mean test result was 6.4, which is very similar to ours. This outcome signifies a moderate stress intensity but with a tendency for a greater one. It was confirmed in our study. It was also found in the work by Cymerys and Olek [24] that obese people are more liable to stress-related factors as $73.2 \%$ of the tested subjects reported a frequent feeling of emotional tension. The study among patients scheduled for bariatric surgery revealed that people suffering from morbid obesity had a higher level of stress, anxiety, depression, food craving, and emotional and behavioural disorder (EBD) symptoms and a lower level of self-esteem and quality of life compared with normal weight controls. Obese patients showed lower physiological and physical well-being, social isolation, dissatisfying relationships, and occupational problems [25]. However, as noted by Mack et al. [19], after these operations depressive symptoms and stress scores improved.

A lot of our patients felt they were unable to control the important things in their lives and could not cope with all the things they had to do. That is confirmed by other authors [19, 21, 25]. What is important, almost half of our respondents stated that their work was associated with high levels of stress. A statistical analysis showed a significant correlation between position at work and stress levels of patients. In contrast to these findings is the result of the patients' appraisal of their own efficiency (coping with duties, personal problems). What may seem astonishing, in this study the great majority of respondents claimed they were able to control their irritation. This may stem from the fact that owing to morbid obesity, which is regarded by the respondents as a kind of defeat, failure to manage problems or indiscipline, they do not want to admit to other problems because they are ashamed of them. They strive to prove their efficiency in different areas of their activities and they are reluctant to admit to their helplessness. It should also be borne in mind that obesity does not exclude occupational success and coping with everyday stress and responsibilities.

Post-surgical mental health appears to be highly relevant in terms of weight loss maintenance. It is likely that the surgical outcomes could be better if patients at risk of developing mental health issues or eating disorders were identified and monitored in order to offer appropriate interventions [19]. A better understanding of the relationship of psycholog- 
ical disorders with weight loss and other outcomes of bariatric surgery may improve patient selection and facilitate more appropriate interventions [24].

\section{Conclusions}

Obese patients demonstrate a tendency for increased feelings of stress and emotional tension. Negative emotions may affect the selection of food and taste preferences. Such emotions cause patients to lose control over the amount of products consumed and they reached more willingly for high-calorie snacks, favouring an increase in their body weight. In the case of obese patients, especially with extreme obesity, it is especially important to control the diet using a method of continuous recording. Recording diet information in nutrition diaries and planning meals may minimise the risk of excessive consumption of food. Psychological support is especially important for patients with extreme obesity. It may help both to change nutrition habits and to cope with stress.

\section{Conflict of interest}

The authors declare no conflict of interest.

\section{References}

1. Ng M, Fleming T, Robinson M, et al. Global, regional, and national prevalence of overweight and obesity in children and adults during 1980-2013: a systematic analysis for the Global Burden of Disease Study 2013. Lancet 2014; 384: 766-81.

2. Łuszczyńska A. Overweight and obesity. Psychological interventions [Polish]. PWN, Warsaw 2007.

3. Luppino FS, de Wit LM, Bouvy PF. Overweight, obesity, and de pression: a systematic review and meta-analysis of longitudinal studies. Arch Gen Psychiatry 2010; 67: 220-9.

4. Yau YHC, Potenza MN. Stress and eating behaviors. Minerva Endocrinol 2013; 38: 255-67.

5. Franken RE. Psychology of motivation [Polish]. GWP, Gdansk 2012

6. Janik MR, Bielecka I, Kwiatkowski A, et al. Cross-sectional study of male sexual function in bariatric patients. Videosurgery Miniinv 2016; 11: 171-7.

7. Buchwald H, Cowan GSM, Pories WJ (eds.). Surgical management of obesity. Saunders Elsevier, Philadelphia 2007.

8. Kalarchian MA, Marcus MD, Levine MD, et al. Psychiatric disorders among bariatric surgery candidates: relationship to obesity and functional health status. Am J Psychiatry 2007; 164: 328-34.

9. Rossetti C, Halfon O, Boutrel B. Controversies about a common etiology for heating and mood disorders. Front Psychol 2014; 5: 1205.

10. Bętkowska-Korpała B. Karpowicz A, Gierowski JK, et al. Stress experience of obese people - an original study [Polish]. En- dokrynologia Otyłość Zaburzenia Przemiany Materii 2007; 3: 63-7.

11. Janik MR, Stanowski E, Paśnik K. Present status of bariatric surgery in Poland. Videosurgery Miniinv 2016; 11: 22-5.

12. Stanowski E, Paśnik K. Bariatric surgery - the current state of knowledge [Polish]. Videosurgery Miniinv 2008; 3: 71-86.

13. Fried M, Hainer V, Basdevant A, et al. Interdisciplinary European guidelines on surgery of severe obesity. Obes Facts 2008; 1: 52-9.

14. Juczyński Z, Ogińska-Bulik N. Tools measuring stress and coping with stress [Polish]. Pracownia Testów Psychologicznych Polskiego Towarzystwa Psychologicznego, Warsaw 2009.

15. Michell JE, King WC, Courcoulas A, et al. Eating behavior and heating disorders in adults prior to bariatric surgery. Int J Eat Disord 2015; 48: 215-22.

16. Ostrowska L, Karczewski J, Szwarc J. Dietary habits as an environmental factor of overweight and obesity [Polish]. Roczn PZH 2007; 58: 307-13.

17. Zunker C, Karr T, Saunders R, Mitchell JE. Eating behaviors post-bariatric surgery: a qualitative study of grazing. Obes Surg 2012; 22: 1225-31.

18. Colles SL, Dixon JB, O’Brien PE. Grazing and loss of control related to eating: two high-risk factors following bariatric surgery. Obesity (Silver Spring) 2008; 16: 615-22.

19. Mack I, Ölschläger S, Sauer H, et al. Does laparoscopic sleeve gastrectomy improve depression, stress and eating behaviour? A 4-year follow-up study. Obes Surg 2016; 26: 2967-73.

20. Mitchell JE, King WC, Courcoulas A, et al. Eating behavior and eating disorders in adults before bariatric surgery. Int J Eat Disord 2015; 48: 215-22.

21. Myers VH, Adams CE, Barbera BL, Brantley PJ. Medical and psychosocial outcomes of laparoscopic Roux-en-Y gastric bypass: cross-sectional findings at 4-year follow-up. Obes Surg 2012; 22: 230-9.

22. Boniecka I, Szczygieł B, Paśnik K. Selected lifestyle characteristic of patients with extreme obesity qualified for bariatric surgery [Polish]. Roczn PZH 2009; 60: 279-84.

23. Zellner DA, Loaiza S, Gonzalez Z, et al. Food selection changes under stress. Physiol Behav 2006; 87: 789-93.

24. Cymerys M, Olek E. The assessment of dietary habits and lifestyle in patients with visceral obesity [Polish]. Przegl Kardiodiabetol 2011; 6: 287-93.

25. Abilés V, Rodríguez-Ruiz S, Abilés J, et al. Psychological characteristics of morbidly obese candidates for bariatric surgery. Obes Surg 2010; 20: 161-7.

26. Lewandowska-Skop A, Gąsior A, Zając J, Sapała K. Assessment of energy and macronutrient intake among overweight and obese women [Polish]. Probl Hig Epidemiol 2014; 95: 975-80.

27. Barrington WE, Ceballos RM, Bishop SK, et al. Perceived stress, behavior, and body mass index among adults participating in a worksite obesity prevention program, Seattle, 2005-2007. Prev Chronic Dis 2012; 9: E152.

28. Born JM, Lemmens SG, Rutters F, et al. Acute stress and food-related reward activation in the brain during food choice during eating in the absence of hunger. Int J Obes (Lond) 2010; 34: 172-81. 
29. Mechanick JI, Youdim A, Jones DB et al. Clinical practice guidelines for the perioperative nutritional, metabolic, and nonsurgical support of the bariatric surgery patient-2013 update: cosponsored by American Association of Clinical Endocrinologists, the Obesity Society, and American Society for Metabolic \& Bariatric Surgery. Surg Obes Relat Dis 2013; 9(2): 159-91.

30. Richardson AS, Arsenault JE, Cates SC, Muth MK. Perceived stress, unhealthy eating behaviors, and severe obesity in lowincome women. Nutr J 2015; 14: 122.

Received: 13.12.2016, accepted: 22.12.2016. 